Check for updates

Cite this: Mater. Adv., 2021, 2, 7932

Received 10th September 2021 Accepted 4th October 2021

DOI: 10.1039/d1ma00836f

rsc.li/materials-advances

\title{
Cation vacancy driven efficient CoFe-LDH-based electrocatalysts for water splitting and $\mathrm{Zn}$-air batteries $\dagger$
}

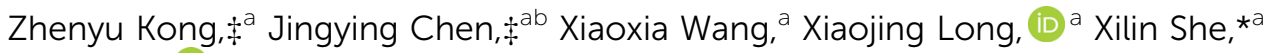 \\ Daohao Li ${ }^{* a}$ and Dongjiang Yang ${ }^{a}$
}

\begin{abstract}
Rational design of multifunctional electrocatalysts can optimize the mutual conversion of water and oxygen. CoFe-LDH-based electrocatalysts with highly tunable electronic, component, and catalytic properties have attracted considerable attention. Herein, we report the synthesis of cation vacancy rich CoFe-LDH (CoFe - -LDH) and its trace Pt loaded material (PtaCoFe - LDH, Pt dosage: 2.85\%), which can act as an efficient electrocatalyst toward the oxygen evolution reaction (OER), hydrogen evolution reaction (HER), and oxygen reduction reaction (ORR). The electrolyzer comprising the $\mathrm{CoFe}_{V}-\mathrm{LDH}$ cathode and Pt@CoFe $\mathrm{V}_{\mathrm{V}} \mathrm{LDH}$ anode exhibited excellent water splitting performance with a small cell voltage of $1.57 \mathrm{~V}$ to reach $10 \mathrm{~mA} \mathrm{~cm}^{-2}$ and $99 \%$ efficiency after $8 \mathrm{~h}$. Furthermore, the liquid-state ZAB using $\mathrm{CoFe}_{\mathrm{V}}-\mathrm{LDH} / / \mathrm{PtCCOFe} \mathrm{V}_{\mathrm{V}} \mathrm{LDH}$ as air electrodes shows satisfactory charge-discharge performance with excellent reversibility of $50 \mathrm{~h}$ at $50 \mathrm{~mA} \mathrm{~cm}{ }^{-2}$.
\end{abstract}

\section{Introduction}

The exploitation and design of efficient catalysts for metal-air cells, fuel cells and water splitting devices has become a potential strategy to address the growing energy needs and environmental remediation of modern society. ${ }^{1-3}$ Among the feasible renewable energy electrocatalytic technologies, the oxygen evolution reaction (OER), hydrogen evolution reaction (HER), and oxygen reduction reaction (ORR) are widely researched in energy conversion processes owing to their internal interrelationship. ${ }^{4-6}$ The extensive application of energy conversion devices (such as fuel cells, zinc-air batteries and full water splitting devices) is impeded by the cost of noble metals. ${ }^{7-9}$ Hence, in consideration of the expense, activity and stability of the above-mentioned devices, catalysts should be designed legitimately in terms of efficiency and cost. Exploring highly efficient electrocatalysts with free or low-dosage noble

\footnotetext{
${ }^{a}$ State Key Laboratory of Bio-fibers and Eco-textiles, Shandong Collaborative Innovation Center of Marine Bio-based Fibers and Ecological Textiles, College of Environmental Science and Engineering, College of Materials Science and Engineering, Qingdao University, Qingdao 266071, P. R. China. E-mail:xlshe@qdu.edu.cn, lidaohao@qdu.edu.cn

${ }^{b}$ Department of Blood Transfusion, The Affiliated Hospital of Qingdao University, Qingdao University, Qingdao 266003, P. R. China

$\dagger$ Electronic supplementary information (ESI) available. See DOI: 10.1039/ d1ma00836f

\$ Zhenyu Kong and Jingying Chen contributed equally to this work.
}

metals for economical energy transformation and storage is mightily desired.

Layered double hydroxides consisting of cheaper transition metals (TM-LDHs) have been typically considered as promising catalysts due to their high electrocatalytic performance and easily tailored structures. ${ }^{10-12}$ Selective alkali etching can specifically remove the target metal (such as $\mathrm{Zn}, \mathrm{Al}$ ) to induce cation vacancies in TM-LDHs (TM $\mathrm{V}_{\mathrm{V}}$-LDHs), which can modulate their chemical coordination and surface electronic states. ${ }^{13,14}$ The unsaturated sites created by the cation vacancies can effectively facilitate the OER process of the electrocatalyst. ${ }^{15}$ However, the HER and ORR catalytic activities of $\mathrm{TM}_{\mathrm{V}}$-LDHs are limited due to the intrinsic nature of TM-LDHs as they do not have adequate active sites. ${ }^{16,17}$

$\mathrm{Pt}$ is one of the most common noble metals with convincing performance for the HER and ORR. However, due to the cost and low utilization rate of $\mathrm{Pt}$, its application in energy conversion devices is limited and promising strategies are desired to replace it or reduce its dosage. Active site-support catalysts driven by cation vacancies have attracted wide attention due to the synergistic interaction between diverse components. ${ }^{18-20}$ The cation vacancy rich metal-based support can not only provide adhesion sites for the externally introduced other components by strong metalsupport interaction (SMSI), but also optimize its internal electron distribution to enhance catalytic activities. ${ }^{21-23}$ Anchoring Pt on cation vacancy rich metal-based support through SMSI can facilitate the efficient utilization of Pt to reduce its dosage and enhance the intrinsic activity of $\mathrm{Pt}^{24,25}$ Thus, trifle Pt coupled with 
vacancies within $\mathrm{TM}_{\mathrm{V}}$-LDHs could show highly efficient HER and ORR performance, and it is meaningful to investigate the electrocatalytic activities of $\mathrm{TM}_{\mathrm{V}}-\mathrm{LDHs}$ with trace $\mathrm{Pt}$ loading to achieve multiple energy conversions.

Herein, we report the cation vacancy rich CoFe-LDH $\left(\mathrm{CoFe}_{\mathrm{V}}-\mathrm{LDH}\right)$ and its trace Pt loaded material (Pt@CoFe $\mathrm{V}^{-}$ LDH, Pt dosage: $2.85 \%$ ) for achieving highly efficient full water splitting and $\mathrm{Zn}$-air batteries (ZABs). The $\mathrm{CoFe}_{\mathrm{V}}-\mathrm{LDH}$ exhibits satisfactory OER performance with a $241 \mathrm{mV}$ overpotential to drive $10 \mathrm{~mA} \mathrm{~cm}^{-2}$. Due to the synergistic effect of Pt and $\mathrm{CoFe}_{\mathrm{V}}-\mathrm{LDH}$ support, the $\mathrm{Pt} @ \mathrm{CoFe}_{\mathrm{V}}-\mathrm{LDH}$ exhibits potential HER and ORR performance. The HER activity of $\mathrm{Pt} @ \mathrm{CoFe}_{\mathrm{V}}-\mathrm{LDH}$ is similar to that of $20 \mathrm{wt} \% \mathrm{Pt} / \mathrm{C}$, which only requires $72 \mathrm{mV}$ to supply $10 \mathrm{~mA} \mathrm{~cm}{ }^{-2}$ current density. When the electrolyzer was composed of the $\mathrm{CoFe}_{\mathrm{V}}-\mathrm{LDH}$ anode and Pt@CoFe $\mathrm{V}_{\mathrm{V}}-\mathrm{LDH}$ cathode, the current density of water splitting reaches $10 \mathrm{~mA} \mathrm{~cm}{ }^{-2}$ at a low voltage of $1.57 \mathrm{~V}$ and remained at $99 \%$ after the $8 \mathrm{~h}$ long-term stability test. The Pt@CoFe $\mathrm{V}_{\mathrm{V}}-\mathrm{LDH}$ shows effective ORR performance in alkaline electrolytes (a half-wave potential of $\sim 0.819 \mathrm{~V}$ ). The turnover frequency (TOF) value of $\mathrm{Pt} @ \mathrm{CoFe}_{\mathrm{V}}-\mathrm{LDH}\left(0.2771 \mathrm{~S}^{-1}\right)$ is about six-fold higher than that of $\mathrm{Pt} / \mathrm{C}\left(0.042 \mathrm{~S}^{-1}\right)$, indicating that the intrinsic activity of $\mathrm{Pt}$ is sufficiently enhanced by the $\mathrm{CoFe}_{\mathrm{V}}-\mathrm{LDH}$ support. The liquidstate $\mathrm{ZAB}$ using $\mathrm{CoFe}_{\mathrm{V}}-\mathrm{LDH} / / \mathrm{Pt} @ \mathrm{CoFe}_{\mathrm{V}}-\mathrm{LDH}$ as air electrodes shows satisfactory charge-discharge performance with excellent reversibility.

\section{Experimental section}

\subsection{Synthesis of CoFeZn layered double hydroxide (CoFeZn-LDH) nanosheets}

CoFe-LDH was prepared according to a classical procedure. At room temperature, $3 \mathrm{mmol}$ of cobalt nitrate hexahydrate, $1 \mathrm{mmol}$ ferric nitrate nonahydrate, and $10 \mathrm{mmol}$ urea were poured into water $(70 \mathrm{~mL})$ and stirred vigorously. The obtained mixture was transferred to a $100 \mathrm{~mL}$ stainless steel autoclave lined with polytetrafluoroethylene (PTFE) and heated at $100{ }^{\circ} \mathrm{C}$ for 12 hours. The obtained CoFe-LDH brown powder was washed three times with water/ethanol and dried at $60{ }^{\circ} \mathrm{C}$ for 6 hours in a vacuum oven. The $\mathrm{Co}_{2} \mathrm{Fe}_{1} \mathrm{Zn}_{1}-\mathrm{LDH}$ was prepared with $2 \mathrm{mmol}$ cobalt nitrate hexahydrate, $1 \mathrm{mmol}$ ferric nitrate nonahydrate, $1 \mathrm{mmol}$ zinc nitrate hexahydrate and $10 \mathrm{mmol}$ urea similarly to that described above. The $\mathrm{Co}_{2.5} \mathrm{Fe}_{1} \mathrm{Zn}_{0.5}-\mathrm{LDH}$ was prepared with $2.5 \mathrm{mmol}$ cobalt nitrate hexahydrate, $1 \mathrm{mmol}$ ferric nitrate nonahydrate, $0.5 \mathrm{mmol}$ zinc nitrate hexahydrate and $10 \mathrm{mmol}$ urea.

\subsection{Synthesis of $\mathrm{CoFe}_{\mathrm{V}}-\mathrm{LDH}$ nanosheets}

To take out the $\mathrm{Zn}^{2+}$, vacancies were created in CoFe-LDHs nanosheets, and the as-obtained CoFeZn-LDH nanosheet precursor was etched by using $6 \mathrm{M} \mathrm{KOH}$ solution (treatment time: $180 \mathrm{~min})$ at $60{ }^{\circ} \mathrm{C}$. The obtained product $\left(\mathrm{CoFe}_{\mathrm{V}}-\mathrm{LDH}\right)$ was washed with water/ethanol three times and dried at $60{ }^{\circ} \mathrm{C}$ for 10 hours in a vacuum oven.

\subsection{Synthesis of Pt@CoFe $\mathrm{V}_{\mathrm{V}}-\mathrm{LDH}$}

Under UV (ultraviolet) irradiation, $\mathrm{CoFe}_{\mathrm{V}}-\mathrm{LDH}$ was put into the $\mathrm{H}_{2} \mathrm{PtCl}_{6}$ aqueous solution. The photoreduction process was performed for $60 \mathrm{~min}$. Then, the $\mathrm{Pt} @ \mathrm{CoFe}_{\mathrm{V}}-\mathrm{LDH}$ powder was obtained after centrifugation and extraction. The sample was cleaned with deionized water and dried in a vacuum oven for 4 hours.

\subsection{Material characterization}

X-ray diffraction (XRD) was performed with a DX2700 at $40 \mathrm{kV}$ and $30 \mathrm{~mA}$ with $\mathrm{Cu} \mathrm{K} \alpha$ radiation $(\lambda=1.5418 \AA)$. The synthetic samples were investigated by using a FEI Magellan 400 field emission scanning electron microscope (FESEM) for obtaining their morphology. A JOEL JEM-2100F scanning transmission electron microscope (STEM) equipped with a Cs probe corrector at $200 \mathrm{Kv}$ was employed to observe their structures. X-ray photoelectron spectroscopy (XPS) was performed using an ESCALAB 250XL electron spectrometer (Thermo Scientific Corporation) with monochromatic $150 \mathrm{~W}$ Al $\mathrm{K} \alpha$ radiation. Inductively coupled plasma (ICP) spectroscopy was performed using a Focused Photonics ICP-5000. The thickness of the nanosheets was recorded using an atomic force microscope (AFM) (Agilent 5400, America). The electrochemical performances were measured using a CHI760E electrochemical work station. Typical specific capacity and discharge curves of the zinc-air battery were investigated using a blue battery test system.

\subsection{Electrochemical measurements}

OER and HER. All of the electrochemical measurements were investigated with a $\mathrm{CHI} 760 \mathrm{E}$ electrochemical workstation. The OER and HER were performed in a three-electrode configuration including working electrodes $\left(\mathrm{CoFe}_{\mathrm{V}}-\mathrm{LDH} /\right.$ carbon paper, $\mathrm{Pt} @$ $\mathrm{CoFe}_{\mathrm{V}}-\mathrm{LDH} /$ carbon paper), the reference electrode $(\mathrm{Ag} / \mathrm{AgCl})$ and the auxiliary electrode (Pt wire). The linear sweep voltammetry (LSV) polarization curves of the as-synthesized catalysts towards the HER and OER were obtained by placing carbon paper $\left(1 \mathrm{mg} \mathrm{cm}^{-2}\right)$ in a $1.0 \mathrm{M} \mathrm{KOH}$ electrolyte. Before testing LSV, the electrode must be used to operate cyclic voltammogram (CV) tests for activization until stable. LSV curves were corrected by resistance compensation, which eliminated the influence of ohmic resistance of the solution.

ORR. The electrocatalytic activities of catalysts toward the ORR were measured in $0.1 \mathrm{M} \mathrm{KOH}$ electrolytes at $25{ }^{\circ} \mathrm{C}$. The catalyst ink was compounded by mixing the catalyst powder $(3 \mathrm{mg})$ with $5 \mathrm{wt} \%$ Nafion solution $(25 \mu \mathrm{L})$, and $50 \%$ ethanol $(500 \mu \mathrm{L})$. The resultant mixture was ultrasonically blended. The RDE measurements were recorded in a one-cell three-electrode device, with $\mathrm{Pt}$ wire and $\mathrm{Ag} / \mathrm{AgCl}$ as the auxiliary and reference electrode, respectively. The mass density of the catalyst coated on the glassy carbon electrode is $480 \mu \mathrm{g} \mathrm{cm}^{-2}$ with a reference of $240 \mu \mathrm{g} \mathrm{cm}^{-2} 20 \mathrm{wt} \% \mathrm{Pt} / \mathrm{C}$. LSV was performed at a scan rate of $10 \mathrm{mV} \mathrm{s}^{-1}$ in $\mathrm{N}_{2}$-saturated or $\mathrm{O}_{2}$-saturated $0.1 \mathrm{M} \mathrm{KOH}$.

The turnover frequency (TOF) value was computed according to the following equation:

$$
\mathrm{TOF}=(\mathrm{z} J \times A) /(4 \times F \times N)
$$


where $J$ is the current density at a given potential $(0.5 \mathrm{~V})$ and $A$ is the effective area of the glassy carbon electrode $\left(0.0707 \mathrm{~cm}^{2}\right)$. 4 represents the number of electron transferred over $\mathrm{O}_{2}$ during reaction per mole. $F$ is the Faraday constant $\left(96485.3 \mathrm{C} \mathrm{mol}^{-1}\right)$. $n$ represents the number of moles for Pt atoms within catalysts.

Zinc-air batteries. Air electrodes were set out by depositing the as-synthetized catalyst ink onto carbon paper evenly and then drying at $100{ }^{\circ} \mathrm{C}$ for $1 \mathrm{~h}$. The loading mass density was $1.0 \mathrm{mg} \mathrm{cm}{ }^{-2}$. Before employing the zinc plate as the anode, it was polished to remove the oxide layer from the surface. The zinc plate and carbon paper with the coated catalyst formed a home-built electrochemical cell with the electrolyte being $6.0 \mathrm{M} \mathrm{KOH}$ and $0.2 \mathrm{M}$ zinc acetate.

\section{Results and discussion}

The synthetic process of the cation vacancy rich Pt@CoFe $\mathrm{V}_{\mathrm{V}}-\mathrm{LDHs}$ is illustrated in Scheme 1. Primarily, a one-pot hydrothermal reaction described in the Experimental section was performed to grow pristine CoFeZn-LDHs. The atomic molar ratio of $\mathrm{Co}: \mathrm{Fe}$ within the original CoFe-LDH is $3: 1$. When the amount of zinc added is one-third of that of cobalt, it is denoted as $\mathrm{Co}_{2} \mathrm{Fe}_{1} \mathrm{Zn}_{1}-$ $\mathrm{LDH}$, and when the molar ratio of $\mathrm{Co} / \mathrm{Zn}$ is 6 , it is denoted as $\mathrm{Co}_{2.5} \mathrm{Fe}_{1} \mathrm{Zn}_{0.5}-\mathrm{LDH}$. Based on the above-mentioned materials, alkali etching was performed to remove $\mathrm{Zn}$ species for creating cation vacancies to generate $\mathrm{CoFe}_{1 / 3} \mathrm{~V}-\mathrm{LDH}$ and $\mathrm{CoFe}_{1 / 6 \mathrm{~V}} \mathrm{LDH}$. The OER performance of these catalyst was optimized due to the formation of unsaturated sites. Finally, cation vacancy rich $\mathrm{CoFe}_{\mathrm{V}}-\mathrm{LDH}$ was impregnated in $\mathrm{H}_{2} \mathrm{PtCl}_{4}$ aqueous solution for photoreduction to form $\mathrm{Pt} @ \mathrm{CoFe}_{1 / 3 v}-\mathrm{LDH}$ and $\mathrm{Pt} @ \mathrm{CoFe}_{1 / 6 \mathrm{v}^{-}}$ $\mathrm{LDH}^{26}{ }^{26}$ The cation vacancy driven $\mathrm{CoFe}_{\mathrm{V}}-\mathrm{LDH}$ introduced $\mathrm{Pt}$ as an exogenous component, exhibiting efficient HER and ORR performances for full water splitting and zinc-air batteries.

Fig. 1a shows the X-ray diffraction (XRD) patterns of CoFe-LDH, CoFeZn-LDH, CoFe $-\mathrm{LDH}$ and Pt@CoFe $-\mathrm{LDH}$. The peaks located at $11.6^{\circ}, 23.4^{\circ}, 34.1^{\circ}, 59^{\circ}$ and $60.54^{\circ}$ correspond to the (003), (006), (012), (110) and (113) planes, respectively, according to the JCPDS \#50-0235. ${ }^{27}$ Although the vacancies created by the alkali etching process destroyed part of the structure, resulting in poor crystallinity, the crystalline image

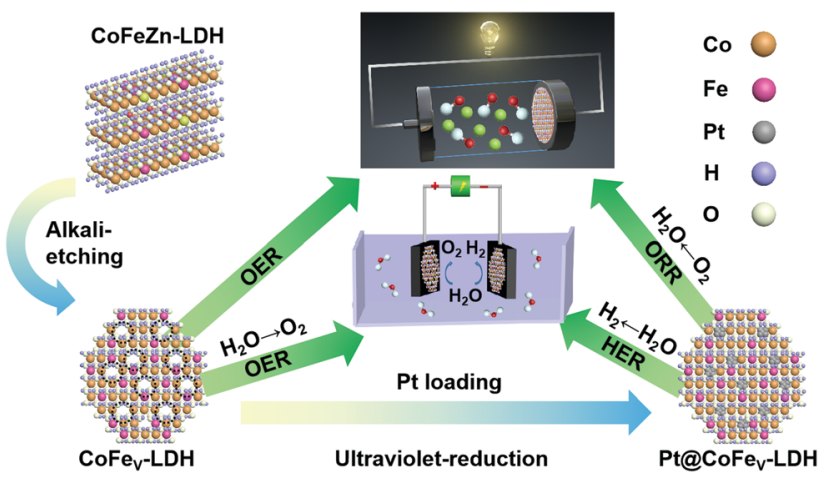

Scheme 1 Schematic illustration of the synthesis process for multifunctional PtaCoFev-LDH.
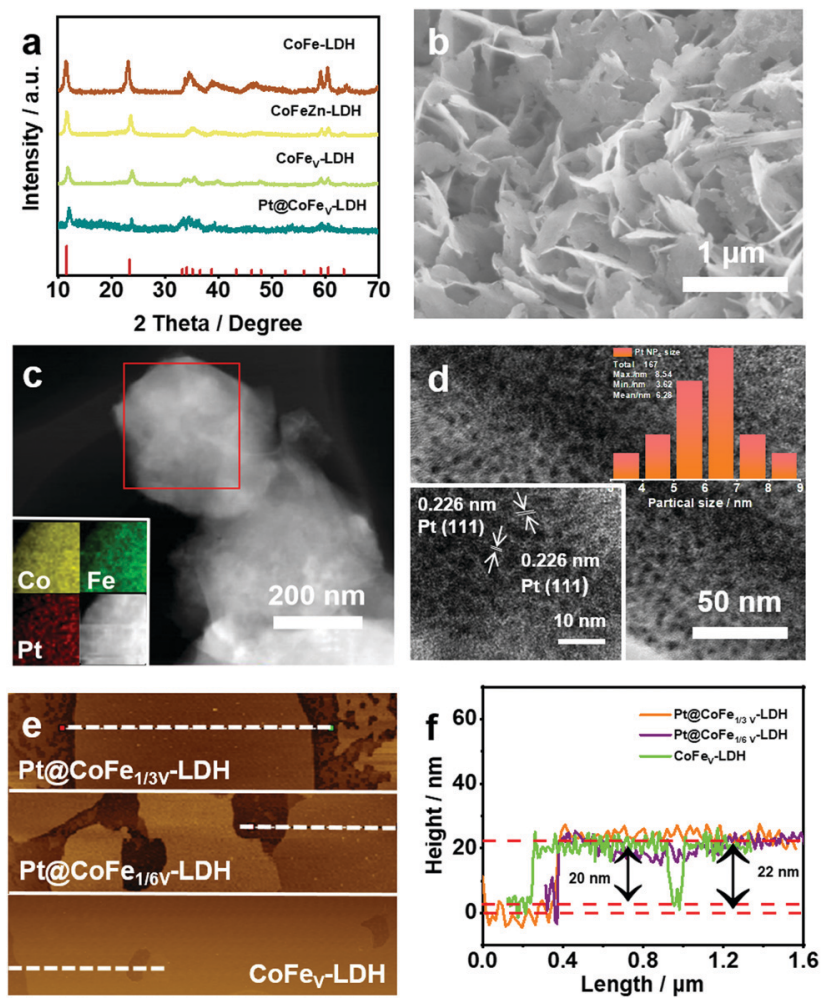

Fig. 1 (a) XRD patterns of CoFe-LDH, CoFeZn-LDH, CoFev-LDH and Pt@CoFe ${ }_{V}-\mathrm{LDH}$. (b) FESEM image of the Pt@CoFe ${ }_{V}-\mathrm{LDH}$ nanosheet. (c) TEM and EDS mapping images, (d) HRTEM of Pt@CoFe ${ }_{V}-$ LDH (inset: lattice space and size distribution of Pt NPs). (e and f) AFM images and curves of $\mathrm{CoFe}_{V}-\mathrm{LDH}$ and Pt@CoFe $-\mathrm{LDH}$

of $\mathrm{CoFe}_{\mathrm{V}} \mathrm{-LDH}$ still remains. The characteristic peak of Pt is not obvious due to the trace amount of Pt injection, with the content of Pt being $2.85 \mathrm{wt} \%$ (detected by ICP). The ratio of Co: $\mathrm{Fe}: \mathrm{Pt}$ in $\mathrm{Pt} @ \mathrm{CoFe}_{1 / 3 \mathrm{~V}} \mathrm{LDH}$ was calculated to be $1: 21: 7.3$ by the ICP test, while that of the Pt@CoFe ${ }_{1 / 6} \mathrm{v}^{-\mathrm{LDH}}$ was 1:18:9.1. The Pt@Co$\mathrm{Fe}_{\mathrm{V}}$-LDH shows a typical $2 \mathrm{D}$ nanosheet morphology (Fig. 1b). ${ }^{28-30}$ The lamellar 2D structure increases the number of active sites exposed. The SEM of $\mathrm{CoFe}_{\mathrm{V}} \mathrm{LDH}$ is shown in Fig. S2 (ESI†). By comparison, the morphology of the catalyst did not change before and after loading Pt. Transmission electron microscopy (TEM) images also confirmed the presence of hexagonal nanosheets (Fig. 1c). And the energy dispersive X-ray spectroscopy (EDS) mappings (inset of Fig. 1c) verified the presence of $\mathrm{Co}, \mathrm{Fe}$ and Pt in equal amounts in the prepared nanosheet. Fig. 1d demonstrates that Pt is present in the form of very fine (5-7 nm) nanoparticles (NPs). The $0.226 \mathrm{~nm}$ lattice spacing corresponds to the (111) plane of Pt (inset of Fig. 1d). ${ }^{31}$ The surface of the $\mathrm{COFe}_{\mathrm{V}}$-LDH edge was observed by HRTEM (Fig. S1, ESI $\dagger$ ), and parallel lattice stripes with an interplanar distance of $0.25 \mathrm{~nm}$ were assigned to the (012) plane of the crystalline CoFe-LDH (inset of Fig. S1, ESI $\dagger$ ). ${ }^{32}$ The thickness of the $\mathrm{CoFe}_{\mathrm{V}}-\mathrm{LDH}$ and $\mathrm{Pt} @ \mathrm{CoFe}_{\mathrm{V}}-\mathrm{LDH}$ nanosheets was detected by AFM to be about 20 and $22 \mathrm{~nm}$ (Fig. 1e and f), indicating that the lamellar structure of $\mathrm{CoFe}_{\mathrm{V}}-\mathrm{LDH}$ was not transformed after Pt loading.

In order to analyse the surface chemical structure of the asprepared samples, X-ray photoelectron spectroscopy (XPS) was 
performed to monitor the valence of metal elements on the surface of the $\mathrm{CoFe}_{\mathrm{V}}-\mathrm{LDH}$ and $\mathrm{Pt} @ \mathrm{CoFe}_{\mathrm{V}}-\mathrm{LDH}$ catalysts. As shown in Fig. 2a, the full XPS survey spectra of samples show strong signals of $\mathrm{Co}, \mathrm{Fe}$ metal elements. The XPS spectrum of Pt@CoFe ${ }_{\mathrm{V}}$-LDH shows two fresh tiny peaks around $71.6 \mathrm{eV}$ and $74.7 \mathrm{eV}$, which are attributed to $\mathrm{Pt} 4 \mathrm{f}$, indicating the successful loading of Pt on the CoFev-LDH support. ${ }^{33}$ Compared with the peak position of the sample before etching, the peaks of $\mathrm{CoFe}_{\mathrm{v}}$-LDH are significantly negatively shifted, which is due to the decrease of the nearby metal valence state caused by the appearance of vacancies. ${ }^{34}$ The XPS spectra of Co $2 p$ exhibited peaks located at $780 \mathrm{eV}, 781.5 \mathrm{eV}, 795.4 \mathrm{eV}$ and $796.6 \mathrm{eV}$, which are assigned to Co $2 \mathrm{p}_{3 / 2}(+3,+2)$ and Co $2 \mathrm{p}_{1 / 2}$ $(+3,+2)$ of Co within $\mathrm{CoFe}_{\mathrm{V}}-\mathrm{LDH}$, and the surrounding two satellite peaks located at $785.9 \mathrm{eV}$ and $801.9 \mathrm{eV}$ (Fig. 2b). ${ }^{35}$ The peaks of Co $2 \mathrm{p}_{3 / 2}$, Co $2 \mathrm{p}_{1 / 2}$ and satellite had a negative shift with different degrees (0.1-0.4 eV). The orbit of $\mathrm{Fe} 2 \mathrm{p}$ was linearly split into $\mathrm{Fe} 2 \mathrm{p}_{3 / 2}(+2,+3)$ at binding energies of $710.6 \mathrm{eV}$ and $713 \mathrm{eV}$, and $\mathrm{Fe} 2 \mathrm{p}_{1 / 2}(+2,+3)$ peaks are located at $722.5 \mathrm{eV}$ and $733 \mathrm{eV}$ (Fig. 2c). ${ }^{36}$ Similar to the trend of the XPS peak shift within $\mathrm{Co}, \mathrm{Fe} 2 \mathrm{p}$ and satellite peaks were negatively shifted. The negative shift of both Fe $2 p$ and Co $2 p$ implied that the effect of etching has not worked for single metals. After Pt loading, the peaks of Co $2 \mathrm{p}$ and Fe $2 \mathrm{p}$ are significantly positively shifted due to the loss of electrons from the metal in the carrier under SMSI, which leads to an increase in the energy band. ${ }^{37}$ The high resolution XPS spectrum of Pt 4f for Pt@CoFe $-\mathrm{LDH}$ (Fig. 2d) displays the spin-orbit doublet with the peaks located at

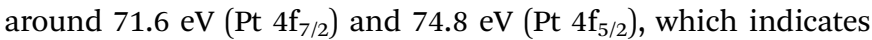
the subsistence of metallic $\mathrm{Pt}^{0}$ (predominant) and $\mathrm{Pt}^{2+}$ species in the composites.

OER plays an important role as one of the two half-reactions of water splitting, thus it is necessary to consider its kinetic factors. The electrocatalytic properties of the as-synthesized CoFe-LDH, CoFeZn-LDH, CoFe $\mathrm{V}_{\mathrm{V}} \mathrm{LDH}$, and Pt@CoFe ${ }_{\mathrm{V}}-\mathrm{LDH}$
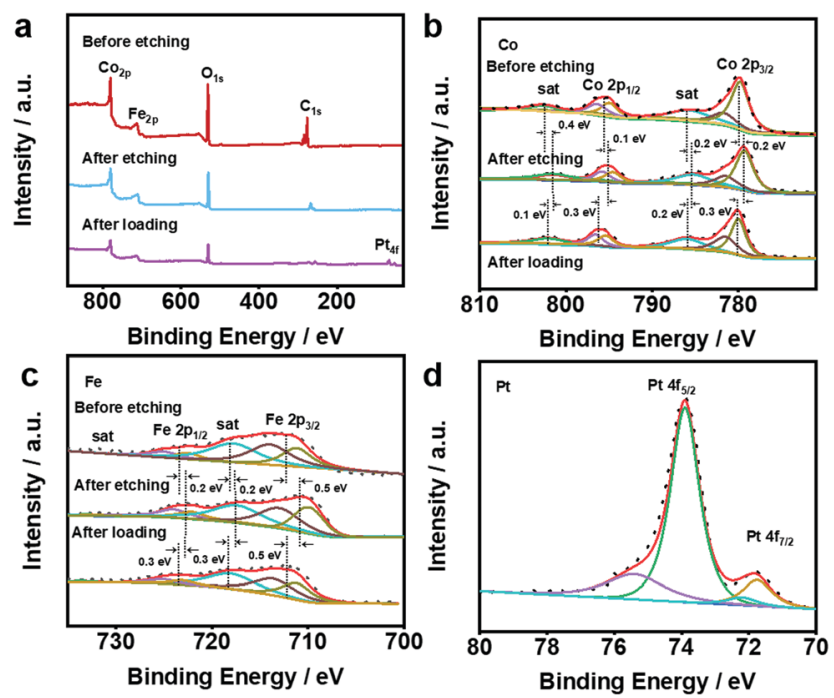

Fig. 2 XPS spectra of (a) the full, (b) Co $2 p$ and (c) Fe $2 p$ within CoFe $\mathrm{V}_{\mathrm{V}} \mathrm{LDH}$ and Pt@CoFe - -LDH. (d) XPS spectra of Pt within Pt@CoFe - LDH.
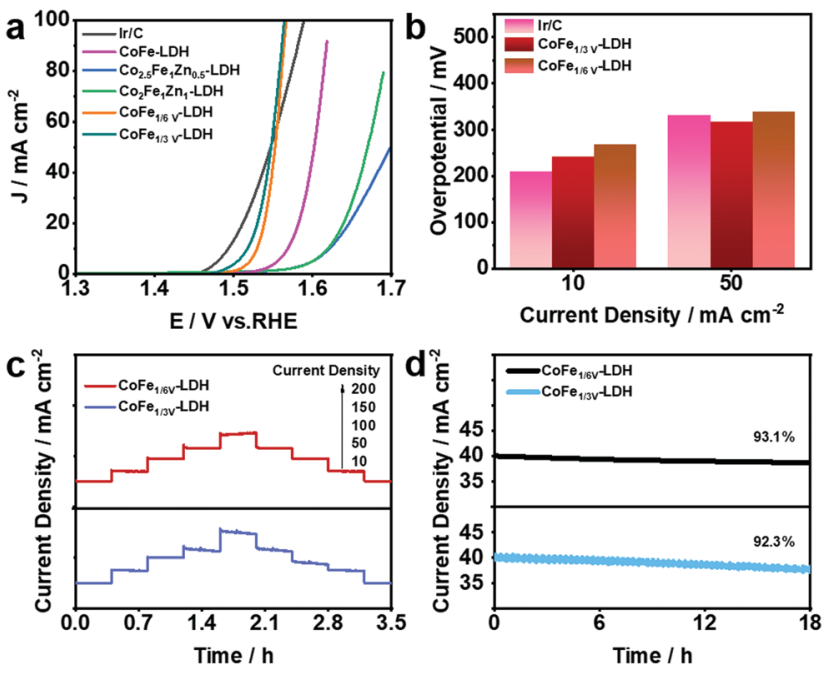

Fig. 3 (a) LSV curves of Ir/C, CoFe-LDH, CoFeZn-LDH and CoFe - -LDH for catalyzing the OER. (b) Histogram of the overpotentials of the $\mathrm{Ir} / \mathrm{C}$ and $\mathrm{CoFe}_{V}-\mathrm{LDH}$ to drive $10 \mathrm{~mA} \mathrm{~cm} \mathrm{~cm}^{-2}$ and $50 \mathrm{~mA} \mathrm{~cm}{ }^{-2}$. (c) Multistep chronoamperometric curves of $\mathrm{CoFe}_{\mathrm{V}}-\mathrm{LDH}$ at different applied potentials. (d) Long-term stability measurement of the $\mathrm{CoFe}_{\mathrm{V}}-\mathrm{LDH}$ for over $18 \mathrm{~h}$.

nanosheets were evaluated by investigating the linear sweep voltammetry (LSV) curves in $1.0 \mathrm{M} \mathrm{KOH}$ solution. As shown in Fig. 3a, the fitted LSV curve for $\mathrm{CoFe}_{1 / 3 \mathrm{~V}}-\mathrm{LDH}$ has a smaller starting potential relative to those of CoFeZn-LDH and CoFe-LDH. Obviously, the doped $\mathrm{Zn}$ occupied the original Co which was the active site, thus the OER performance of CoFe-LDH was inhibited. Moreover, the overpotential of $\mathrm{CoFe}_{1 / 3 \mathrm{v}} \mathrm{LDH}$ is demonstrated to drive $241 \mathrm{mV}$ at a current density of $10 \mathrm{~mA} \mathrm{~cm}{ }^{-2}$ $\left(\mathrm{CoFe}_{1 / \mathrm{G}} \mathrm{LDH}, 267 \mathrm{mV}\right)$ (Fig. 3b). The overpotential (317 mV) required for $\mathrm{CoFe}_{1 / 3 \mathrm{~V}} \mathrm{VDH}$ to supply $50 \mathrm{~mA} \mathrm{~cm}{ }^{-2}$ current density was lower than that of $\mathrm{Ir} / \mathrm{C}(330 \mathrm{mV})$, indicating that the kinetic advantage of $\mathrm{CoFe}_{\mathrm{V}}-\mathrm{LDH}$ is shown with the increase of current density. The cation vacancies play a vital role in optimizing the OER performance by facilitating the adsorption of OER intermediates, which is consistent with the results reported by others. ${ }^{38}$ In addition, the OER performance of $\mathrm{CoFe}_{1 / 3 \mathrm{~V}}-\mathrm{LDH}$ is better than that of $\mathrm{CoFe}_{1 / 6 \mathrm{~V}}-\mathrm{LDH}$, which reflects the importance for density regulation of vacancies. However, after Pt loading, the OER performance of Pt@ $\mathrm{CoFe}_{\mathrm{V}}$-LDH became slightly worse, as the active sites were provided by the cation vacancies (Fig. S3 and S4, ESI $\dagger$ ). The

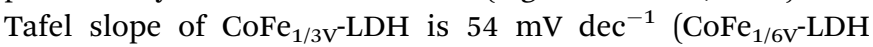
$\left.61 \mathrm{mV} \mathrm{dec}^{-1}\right)$, which is lower than that of $\mathrm{Ir} / \mathrm{C}\left(65 \mathrm{mV} \mathrm{dec}^{-1}\right)$ (Fig. S5, ESI $\dagger$ ). The excellent Tafel slope proved the electron transfer ability of $\mathrm{CoFe}_{\mathrm{V}}$-LDH which was optimized by etching. Fig. $3 \mathrm{c}$ shows that the current density of the $\mathrm{CoFe}_{\mathrm{v}}-\mathrm{LDH}$ catalyst increases accordingly with different applied potentials $(10,50$, 100,150 , and $200 \mathrm{~mA} \mathrm{~cm}$ ), and the reverse process is consistent with the previous performance, indicating the reversible stability of the catalyst. ${ }^{39}$ In addition, compared to Pt loading before, the current density fitted curves of $\mathrm{Pt} @ \mathrm{CoFe}_{\mathrm{v}}-\mathrm{LDH}$ became smoother in the reverse process (Fig. S6 and S7, ESI $\dagger$ ). The linear scanning voltammograms (LSV) of Pt@CoFe ${ }_{v}$-LDH before and after 1000 cyclic 
voltammograms (CV) were unchanged (Fig. S8 and S9, ESI $\dagger$ ). In long-term stability experiments for the OER (Fig. 3d), $\mathrm{CoFe}_{\mathrm{V}^{-}}$ LDH $(1 / 6 \mathrm{~V}, \sim 93.1 \% ; 1 / 3 \mathrm{~V}, \sim 92.3 \%)$ and Pt@CoFe $\mathrm{V}_{\mathrm{V}} \mathrm{LDH}$ (Fig. S10 and S11 (ESI $\dagger$ ), 1/6 V, 99.1\%; 1/3 V, 94.2\%) maintained a stable current density after $18 \mathrm{~h}$. The Pt@Co$\mathrm{Fe}_{\mathrm{V}}$-LDH showed perfectly reproducible performance in the reversible process and long-term stability experiments, demonstrating that Pt anchoring within the vacancies of CoFe-LDH by SMSI facilitates the structural stability of the catalyst with optimized electron distribution.

The HER performance of the synthesized electrocatalysts and $\mathrm{Pt} / \mathrm{C}$ was investigated with a three-electrode system in 1.0 M KOH. Fig. 4a shows the LSV curves of Pt/C, CoFe-LDH, CoFeZn-LDH, $\mathrm{CoFe}_{\mathrm{V}}-\mathrm{LDH}$, and Pt@CoFe ${ }_{\mathrm{V}}-\mathrm{LDH}$. The CoFe-LDH and support have poor electrocatalytic hydrogen release properties, and the coexistence of slight Pt active site loading promotes the intrinsic HER activity. Compared to Pt/C (45 mV), the Pt@CoFe ${ }_{1 / 3 V^{-}}$ $\mathrm{LDH}$ exhibits a low overpotential of $72 \mathrm{mV}$ ( $\mathrm{Pt} @ \mathrm{CoFe}_{1 / 6 \mathrm{~V}} \mathrm{LDH}$, $73 \mathrm{mV}$ ) to supply $10 \mathrm{~mA} \mathrm{~cm}{ }^{-2}$. Also, the same trend for the overpotential is observed at $50 \mathrm{~mA} \mathrm{~cm}$ c $^{-2}$ (Fig. 4b). The Tafel

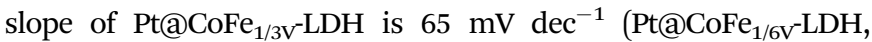
$\left.71 \mathrm{mV} \mathrm{dec}{ }^{-1}\right)$, which is higher than that of $\mathrm{Pt} / \mathrm{C}\left(43 \mathrm{mV} \mathrm{dec}{ }^{-1}\right)$, which manifested that the HER process of the as-prepared samples abided by the combined Volmer-Heyrovsky pathway, whereas that of Pt/C followed the Tafel mechanism (Fig. 4c). ${ }^{40}$ The anchoring of trace Pt within the surface of $\mathrm{CoFe}_{\mathrm{V}}-\mathrm{LDH}$ not only promotes the intrinsic activity of hydrogen evolution but also optimizes the stability, which is more beneficial for practical applications. After 24 hours of the uninterrupted chronopotentiometric (CA) test, Pt@CoFe $\mathrm{C}_{1 / 3 \mathrm{~V}^{-}} \mathrm{LDH}$ showed $\sim 96.1 \%$ efficiency (Pt@CoFe ${ }_{1 / 6 \mathrm{~V}^{-}}$ $\mathrm{LDH}, \sim 92.4 \%$ ) with no significant current decay, proving the longterm stability of the catalyst (Fig. $4 \mathrm{~d}$ ). In contrast, the performance of $\mathrm{CoFe}_{1 / 3 \mathrm{~V}}-\mathrm{LDH}$ decayed to $\sim 82.5 \%$ significantly after the long stability test $\left(\mathrm{CoFe}_{1 / 6 \mathrm{~V}}-\mathrm{LDH}, \sim 83.3 \%\right)$ probably due to the
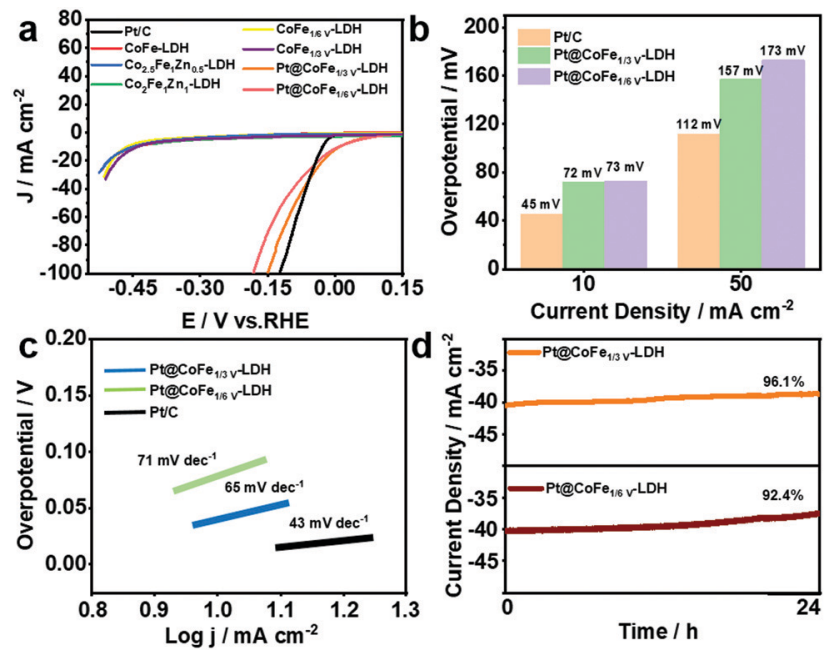

Fig. 4 (a) LSV curves of Pt/C, CoFe-LDH, CoFeZn-LDH, CoFe ${ }_{V}-L D H$ and Pt@CoFe $\mathrm{V}_{\mathrm{V}}-\mathrm{LDH}$ for catalyzing the HER in $1.0 \mathrm{M} \mathrm{KOH}$. (b) Histogram of the overpotentials of the $\mathrm{Pt} / \mathrm{C}$ and synthesized nanomaterials to drive $10 \mathrm{~mA} \mathrm{~cm}^{-2}$ and $50 \mathrm{~mA} \mathrm{~cm}^{-2}$. (c) Tafel slopes of Pt/C and Pt@CoFe $-\mathrm{LDH}$. (d) Long-term stability measurement of the Pt@CoFe $\mathrm{V}_{\mathrm{V}} \mathrm{LDH}$ for over $24 \mathrm{~h}$. transformation near the unsaturated sites that deformed the catalyst structure, ${ }^{41}$ demonstrating that Pt anchoring in vacancies facilitates the structural stability (Fig. S12 and S13, ESI $\dagger$ ). The LSV curves of Pt@CoFe $\mathrm{V}_{\mathrm{V}} \mathrm{LDH}$ before and after $1000 \mathrm{CV}$ cycles have no significant change, thus demonstrating its excellent stability (Fig. S14 and S15, ESI $\dagger$ ).

To further enhance the versatility of the catalyst, the ORR performance of $\mathrm{Pt} @ \mathrm{CoFe}_{\mathrm{V}}-\mathrm{LDH}$ was investigated in $0.1 \mathrm{M} \mathrm{KOH}$ solution (Fig. 5a). The LSV curves of the Pt@CoFe $\mathrm{Cov}_{1 / 3 \mathrm{~V}}-\mathrm{LDH}$ were also obtained in the range of 400 to $2500 \mathrm{rpm}$ under $\mathrm{O}_{2}$ saturated alkaline conditions (Fig. 5b). As the rotation speed of the glassy carbon electrode increases, the corresponding fitted Koutecky-Levich $(K-L)$ plots all show a good linear relationship (inset of Fig. $5 \mathrm{~b}$ ). The electron transfer number $(n)=3.89 \pm 0.02$ was calculated using the slope of the $K-L$ curve, and $R^{2}=0.9998$. The LSV curves recorded with a rotation speed of the electrode of $1600 \mathrm{rpm}$ manifest that the ORR performance of $\mathrm{Pt} @ \mathrm{CoFe}_{\mathrm{V}}-\mathrm{LDH}$ is close to that of $20 \% \mathrm{Pt} / \mathrm{C}$ (a half-wave potential $\left(E_{1 / 2}\right)$ of $0.819 \mathrm{~V}$ ( $v s$. RHE) for Pt@ $\mathrm{CoFe}_{1 / 3 \mathrm{~V}}-\mathrm{LDH}$ and $0.801 \mathrm{~V}$ (vs. RHE) for Pt@CoFe ${ }_{1 / 6 \mathrm{~V}}-\mathrm{LDH}$ ), only $11 \mathrm{mV}$ and $29 \mathrm{mV}$ less than that of $\mathrm{Pt} / \mathrm{C}(0.83 \mathrm{~V})$ (Fig. 5c). The Tafel slope of Pt@CoFe ${ }_{1 / 3 v^{-}} \mathrm{LDH}$ is $58 \mathrm{mV} \mathrm{dec}^{-1}$, which is close to that of $\mathrm{Pt} / \mathrm{C}\left(56 \mathrm{mV} \mathrm{dec}{ }^{-1}\right)$ and better than that of Pt@CoFe ${ }_{1 / 6 \mathrm{~V}}-\mathrm{LDH}$ (65 mV dec ${ }^{-1}$ ) (Fig. 5d), further manifesting the fast ORR kinetics of Pt@CoFe ${ }_{\mathrm{V}}-\mathrm{LDH}$. The intrinsic competence of Pt@CoFe $\mathrm{V}_{\mathrm{V}} \mathrm{LDH}$ was evaluated by the turnover frequency (TOF)
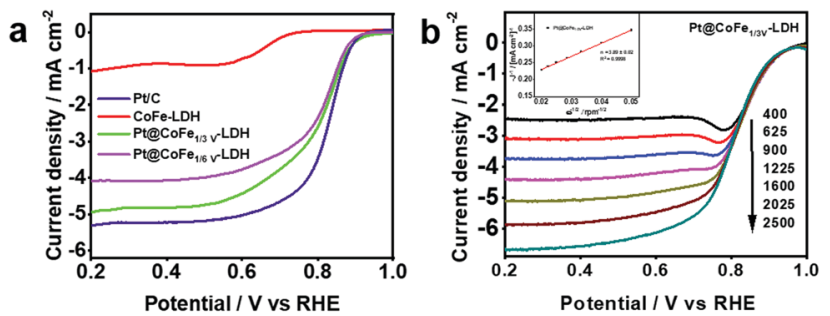

C
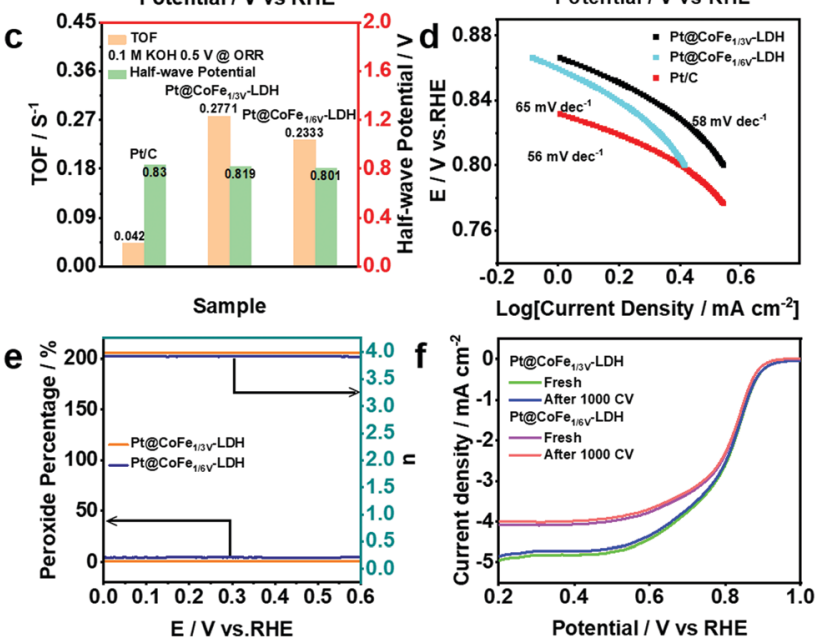

Fig. 5 (a) LSV curves of Pt/C, CoFe-LDH and Pt@CoFe - LDH. (b) LSV curves of Pt@CoFe $e_{1 / 3 v}-\mathrm{LDH}$ at various rotation speeds (inset: $K-L$ plots for Pt@CoFe ${ }_{1 / 3 v}-\mathrm{LDH}$ at $0.2 \mathrm{~V}$ vs. RHE). (c) Turnover frequency (TOF) and half-wave potential of $\mathrm{Pt} / \mathrm{C}$ and PtaCoFe$-\mathrm{LDH}$. (d) Tafel plots. (e) Peroxide percentage, electron transfer number and ( $f$ ) LSV curves before and after $1000 \mathrm{CVs}$ of PtaCoFe $\mathrm{V}_{\mathrm{L}} \mathrm{LDH}$. 

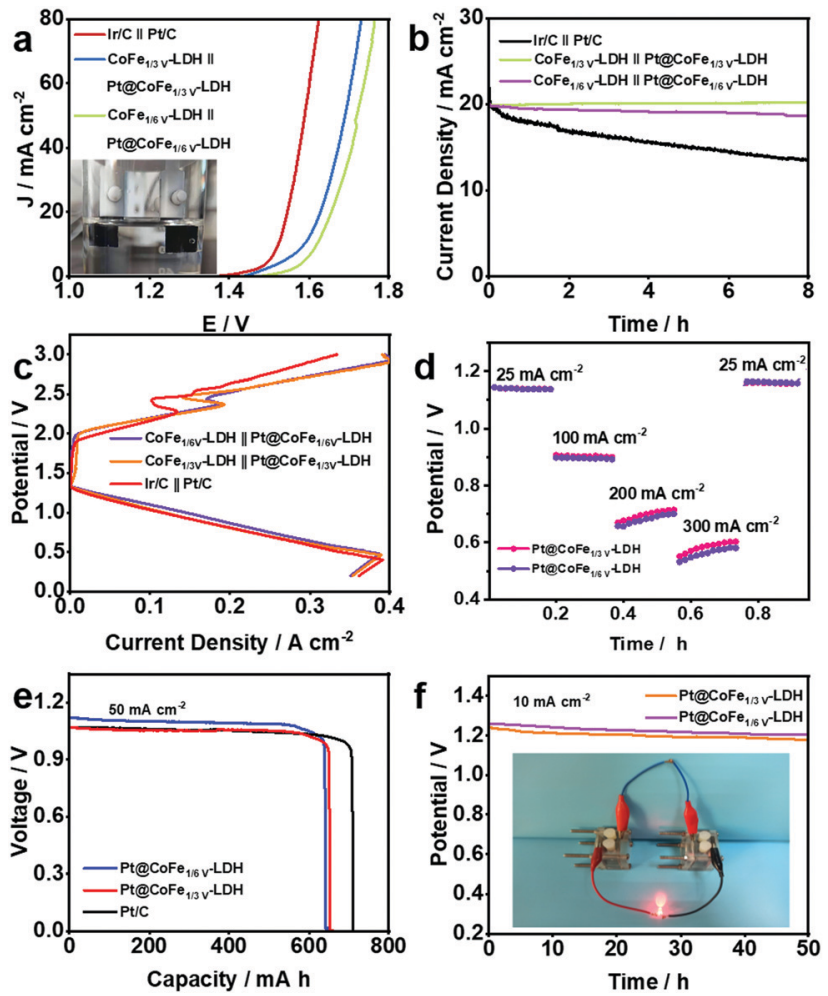

Fig. 6 (a) LSV curves and (b) long-term stability test for full water splitting of the composited catalyst and $\mathrm{Ir} / \mathrm{C} / / \mathrm{Pt} / \mathrm{C}$ in $1 \mathrm{M} \mathrm{KOH}$. (c) Discharge and charge polarization curves of the rechargeable battery using the $\mathrm{CoFe}_{V^{-}}$ $\mathrm{LDH} / / \mathrm{Pt} \mathrm{aCoFe} \mathrm{V}_{\mathrm{V}}-\mathrm{LDH}$ and $\mathrm{Ir} / \mathrm{C} / / \mathrm{Pt} / \mathrm{C}$ air electrodes. (d) Discharged curves from 25 to $300 \mathrm{~mA} \mathrm{~cm}^{-2}$. (e) Typical specific capacity (normalized to the mass of the zinc electrode) curves of the battery using the Pt@CoFe $\mathrm{V}_{\mathrm{V}} \mathrm{LDH}$ air electrode at $50 \mathrm{~mA} \mathrm{~cm}^{-2}$ current densities. (f) The discharge curve of a Pt@CoFe ${ }_{V}-\mathrm{LDH}$-based ZAB over $50 \mathrm{~h}$ and a picture of a LED bulb offering power by two ZABs in series.

over $0.5 \mathrm{~V}$ vs. RHE, which hypothesized that total Pt acted as active sites in the Pt@CoFe $\mathrm{V}_{\mathrm{V}} \mathrm{LDH}$. As shown in Fig. 5c, the TOF value of $\mathrm{Pt} @ \mathrm{CoFe}_{1 / 3 \mathrm{v}^{-}} \mathrm{LDH}$ is $0.2771 \mathrm{~S}^{-1}$, indicating that active sites were more and sufficient to utilize compared to those of $\mathrm{Pt} @ \mathrm{CoFe}_{1 / 6 \mathrm{~V}} \mathrm{LDH}\left(0.2333 \mathrm{~S}^{-1}\right)$.

Rotating ring-disk electrode (RRDE) voltammograms of $\mathrm{Pt} @ \mathrm{CoFe}_{\mathrm{V}}-\mathrm{LDH}$ were obtained in the $0.1 \mathrm{M} \mathrm{KOH}$ electrolyte with oxygen saturation. The electron-transfer number was calculated exactly with a $1600 \mathrm{rpm}$ rotation rate. The electrontransfer numbers of $\mathrm{Pt} @ \mathrm{CoFe}_{1 / 3 \mathrm{v}}-\mathrm{LDH}$ and $\mathrm{Pt} @ \mathrm{CoFe}_{1 / 6 \mathrm{~V}}-\mathrm{LDH}$ were calculated to be 3.92 and 3.87 over the potential range from 0 to $0.6 \mathrm{~V}$ (RHE), and the $\mathrm{H}_{2} \mathrm{O}_{2}$ yield remained below $2 \%$ (Fig. 5e). Moreover, the LSV curves of Pt@CoFe $\mathrm{V}_{\mathrm{V}} \mathrm{LDH}$ before and after 1000 cycles of CV indicate that the ORR stability of $\mathrm{Pt} @ \mathrm{CoFe}_{\mathrm{V}}-\mathrm{LDH}$ is appreciable (Fig. 5f). The trace Pt anchored within the cation vacancies led to an effective ORR performance with $\mathrm{CoFe}_{\mathrm{V}}-\mathrm{LDH}$ in alkaline electrolytes, although it cannot match that of commercial $\mathrm{Pt} / \mathrm{C}$.

On the premise of the remarkable electrocatalytic activity of the synthesized CoFe-LDH-based catalysts towards the HER and OER, full water splitting reactions were performed in 1.0 $\mathrm{M} \mathrm{KOH}$ using the $\mathrm{Pt} @ \mathrm{CoFe}_{\mathrm{V}}-\mathrm{LDH}$ as the cathode and
$\mathrm{CoFe}_{\mathrm{V}}-\mathrm{LDH}$ as the anode for an electrolyzer (Fig. 6a). Only a small cell voltage of $1.57 \mathrm{~V}$ is needed to supply $10 \mathrm{~mA} \mathrm{~cm}{ }^{-2}$ for the electrolyser containing $\mathrm{CoFe}_{1 / 3 \mathrm{~V}^{-}} \mathrm{LDH} / / \mathrm{Pt} @ \mathrm{CoFe}_{1 / 3 \mathrm{~V}^{-}} \mathrm{LDH}\left(\mathrm{CoFe}_{1 / 6 \mathrm{~V}^{-}}\right.$ $\mathrm{LDH} / / \mathrm{Pt} @ \mathrm{CoFe}_{1 / 6 \mathrm{~V}}-\mathrm{LDH}, 1.62 \mathrm{~V}$ ) and the electrogenerated gas bubbles were clearly detected in Fig. 6a illustration. Moreover, $\mathrm{CoFe}_{1 / 3 \mathrm{v}}-\mathrm{LDH} / / \mathrm{Pt} @ \mathrm{CoFe}_{1 / 3 \mathrm{v}}-\mathrm{LDH}$ also demonstrated excellent stability at $\sim 99 \%\left(\mathrm{CoFe}_{1 / 6 \mathrm{~V}}-\mathrm{LDH} / / \mathrm{Pt} @ \mathrm{CoFe}_{1 / 6 \mathrm{~V}}-\mathrm{LDH}, \sim 94.7 \%\right)$ during the $8 \mathrm{~h}$ full water-splitting process (Fig. 6b).

Distinctively, the kinetics in a rechargeable $\mathrm{Zn}$-air battery (ZAB) is primarily confined by the oxygen reaction occurring in the cathode: $\mathrm{O}_{2}+2 \mathrm{H}_{2} \mathrm{O}+4 \mathrm{e}^{-} \rightleftharpoons 4 \mathrm{OH}^{-} \cdot{ }^{42}$ On account of the satisfactory ORR catalytic performance of the Pt@ $\mathrm{CoFe}_{\mathrm{V}}-\mathrm{LDH}$, a liquid ZAB was also established, which broadens its potential for the manufacture of a practical device. As expected, the $\mathrm{Pt} @ \mathrm{CoFe}_{1 / 3 \mathrm{~V}}-\mathrm{LD}$-based $\mathrm{ZAB}$ displays an extreme power density of $200 \mathrm{~mW} \mathrm{~cm}^{-2}$ (Pt@CoFe $\mathrm{Cov}_{1 / 6}-\mathrm{LDH}, 190 \mathrm{~mW} \mathrm{~cm}^{-2}$ ) with a $350 \mathrm{~mA} \mathrm{~cm}{ }^{-2}$ cut-off current density (Pt@CoFe ${ }_{1 / 6 \mathrm{~V}}-\mathrm{LDH}$, $390 \mathrm{~mA} \mathrm{~cm}^{-2}$ ) (Fig. 6c), which is relevant to $105.3 \%$ (Pt@CoFe ${ }_{1 / 6 \mathrm{~V}}-\mathrm{LDH}, 100 \%$ ) for the $\mathrm{ZAB}$ based on a commercial

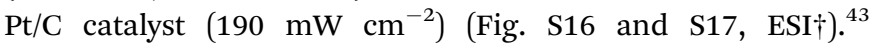
Discharge and charge polarization curves of the rechargeable battery using the $\mathrm{CoFe}_{\mathrm{V}}-\mathrm{LDH} / / \mathrm{Pt} @ \mathrm{CoFe}_{\mathrm{V}}-\mathrm{LDH}$ and $\mathrm{Ir} / \mathrm{C} / / \mathrm{Pt} / \mathrm{C}$ air electrodes are shown in Fig. 6c. The discharge and charge performances of the as-synthetic catalyst exhibit potential overpotentials, which are consistent with the OER and ORR performance of $\mathrm{CoFe}_{\mathrm{V}}-\mathrm{LDH}$ and $\mathrm{Pt} @ \mathrm{CoFe}_{\mathrm{V}}-\mathrm{LDH}$. The Pt@Co$\mathrm{Fe}_{\mathrm{V}}$-LDH-based ZAB can be discharged from 25 to $300 \mathrm{~mA} \mathrm{~cm}^{-2}$ (Fig. 6d), suggesting that it can be operated in a wide range of current densities. Additionally, the specific capacity (normalized to the mass of the zinc electrode) of the Pt@CoFe $\mathrm{Cov}_{1 / 3 \mathrm{~V}}-\mathrm{LDH}$ battery is $\sim 646.8$ ( $\mathrm{Pt} @ \mathrm{CoFe}_{1 / 6 \mathrm{~V}}-\mathrm{LDH}, \sim 641.3 \mathrm{~mA} \mathrm{~h} \mathrm{~g}{ }^{-1}$ ) at $50 \mathrm{~mA} \mathrm{~cm}{ }^{-2}$ current density (Fig. 6e). The potentials of $\mathrm{Pt} @ \mathrm{CoFe}_{1 / 3 \mathrm{~V}}-\mathrm{LDH}$ and $\mathrm{Pt} @ \mathrm{CoFe}_{1 / 6 \mathrm{~V}}-\mathrm{LDH}$ are 1.24 and $1.28 \mathrm{~V}$, respectively, at $10 \mathrm{~mA} \mathrm{~cm}{ }^{-2}$ after $50 \mathrm{~h}$ (Fig. 6f). Two seriesconnected Pt@CoFe $\mathrm{V}_{\mathrm{V}} \mathrm{LDH}$ ZABs can light a LED bulb (Fig. 6f inset), which demonstrated that it can be practically applied in metal-air batteries.

\section{Conclusions}

In summary, we have synthesized high-efficiency cation vacancy rich $\mathrm{CoFe}_{\mathrm{V}}-\mathrm{LDH}$ and $\mathrm{Pt} @ \mathrm{CoFe}_{\mathrm{V}}-\mathrm{LDH}$ electrocatalysts, among which the $\mathrm{CoFe}_{\mathrm{V}}-\mathrm{LDH}$ showed excellent OER performance due to cation vacancies providing affluent active sites and $\mathrm{Pt} @ \mathrm{CoFe}_{\mathrm{V}}-\mathrm{LDH}$, which is demonstrated for catalyzing the HER and ORR, exhibited efficient HER and ORR catalytic activities derived from the anchored Pt on cation vacancies of $\mathrm{CoFe}_{\mathrm{V}}-\mathrm{LDH}$. More importantly, the electrolyzer composed of the $\mathrm{CoFe}_{\mathrm{V}}-\mathrm{LDH}$ anode and the $\mathrm{Pt} @ \mathrm{CoFe}_{\mathrm{V}}-\mathrm{LDH}$ cathode showed excellent water splitting performance and stability. The liquid-state $\mathrm{ZAB}$ using $\mathrm{CoFe}_{\mathrm{V}}-\mathrm{LDH} / /$ $\mathrm{Pt} @ \mathrm{CoFe}_{\mathrm{V}}-\mathrm{LDH}$ as air electrodes showed satisfactory chargedischarge performance. Moreover, Pt@CoFe $\mathrm{V}_{\mathrm{V}} \mathrm{LDH}$ revealed sufficient potential and feasibility in liquid ZAB systems. This work provides a new strategy for the wide application of active sites-support catalysts in energy conversion and storage. 


\section{Conflicts of interest}

There are no conflicts to declare.

\section{Acknowledgements}

This work is financially supported by the National Natural Science Foundation of China (No. 51672143 and 51808303), the Natural Science Foundation of Shandong Province (ZR2017MEM018, ZR2018BEM002, ZR2019BEE027 and ZR2019BC007), the Taishan Scholars Program, Key Research and Development Program of Shandong Province (No. 2017GSF18128), and the State Key Laboratory of Bio-Fibers and Eco-Textiles, Qingdao University (No. ZKT10 and GZRC202006).

\section{Notes and references}

1 M. Ahsan, A. Santiago, Y. Hong, N. Zhang, M. Cano, E. Rodriguez-Castellon, L. Echegoyen, S. Sreenivasan and J. Noveron, J. Am. Chem. Soc., 2020, 142, 14688-14701.

2 Y. Guo, P. Yuan, J. Zhang, H. Xia, F. Cheng, M. Zhou, J. Li, Y. Qiao, S. Mu and Q. Xu, Adv. Funct. Mater., 2018, 28, 1805641.

3 J. Fu, F. Hassan, J. Li, D. Lee, A. Ghannoum, G. Lui, M. Hoque and Z. Chen, Adv. Mater., 2016, 28, 6420.

4 X. Long, D. Li, B. Wang, Z. Jiang, W. Xu, B. Wang, D. Yang and Y. Xia, Angew. Chem., Int. Ed., 2019, 58, 11369-11373.

5 H. Wang, J. Wang, Y. Pi, Q. Shao, Y. Tan and X. Huang, Angew. Chem., Int. Ed., 2019, 58, 2316-2320.

6 D. Li, C. Li, L. Zhang, H. Li, L. Zhu, D. Yang, Q. Fang, S. Qiu and X. Yao, J. Am. Chem. Soc., 2020, 142, 8104-8108.

7 H. Sun, M. Wang, S. Zhang, S. Liu, X. Shen, T. Qian, X. Niu, J. Xiong and C. Yan, Adv. Funct. Mater., 2021, 31, 2006533.

8 C. Zhang, Y. Cui, Y. Yang, L. Lu, S. Yu, Z. Meng, Y. Wu, Y. Li, Y. Wang, H. Tian and W. Zheng, Adv. Funct. Mater., 2021, 2105372, DOI: 10.1002/adfm.202105372.

9 Y. Zhou, S. Sun, C. Wei, Y. Sun, P. Xi, Z. Feng and Z. Xu, Adv. Mater., 2019, 31, 1902509.

10 Z. Cai, D. Zhou, M. Wang, S. Bak, Y. Wu, Z. Wu, Y. Tian, X. Xiong, Y. Li, W. Liu, S. Siahrostami, Y. Kuang, X. Yang, H. Duan, Z. Feng, H. Wang and X. Sun, Angew. Chem., Int. Ed., 2018, 57, 9392-9396.

11 X. Zhang, Y. Zhao, Y. Zhao, R. Shi, G. I. N. Waterhouse and T. Zhang, Adv. Energy Mater., 2019, 9, 1900881.

12 A. Karmakar, K. Kannimuthu, S. Sam Sankar, K. Sangeetha, R. Madhu and S. Kundu, J. Mater. Chem. A, 2021, 9, 1314-1352.

13 Y. Zhao, L. Zheng, R. Shi, S. Zhang, X. Bian, F. Wu, X. Cao, G. Waterhouse and T. Zhang, Adv. Energy Mater., 2020, 10, 2002199.

14 Q. Xie, Z. Cai, P. Li, D. Zhou, Y. Bi, X. Xiong, E. Hu, Y. Li, Y. Kuang and X. Sun, Nano Res., 2018, 11, 4524-4534.

15 Y. Wang, M. Qiao, Y. Li and S. Wang, Small, 2018, 1800136. 16 F. Wang, G. Xu, Y. He, Z. Liu, Z. Zhang, Q. Mao and Y. Huang, J. Energy Chem., 2020, 51, 101-104.

17 G. Tomboc, J. Kim, Y. Wang, Y. Son, J. Li, J. Y. Kim and K. Lee, J. Mater. Chem. A, 2021, 9, 4528.

18 J. Wu, P. Bag, Y. Xu, L. Gong, C. He, X. Chen and J. Zhang, Adv. Mater., 2021, 33, 2007368.
19 J. Zhang, H. Wang, L. Wang, S. Ali, C. Wang, L. Wang, X. Meng, B. Li, D. S. Su and F. S. Xiao, J. Am. Chem. Soc., 2019, 141, 2975-2983.

20 L. Hu, R. Xiao, X. Wang, X. Wang, C. Wang, J. Wen, W. Gu and C. Zhu, Appl. Catal., B, 2021, 298, 120599.

21 H. Chen, Z. Yang, X. Wang, F. Polo-Garzon, P. Halstenberg, T. Wang, X. Suo, S. Yang, H. Meyer III, Z. Wu and S. Dai, J. Am. Chem. Soc., 2021, 143, 8521-8526.

22 P. Kuang, Y. Wang, B. Zhu, F. Xia, C. Tung, J. Wu, H. Chen and J. Yu, Adv. Mater., 2021, 33, 2008599.

23 J. Yang, W. Li, S. Tan, K. Xu, Y. Wang, D. Wang and Y. Li, Angew. Chem., Int. Ed., 2021, 60, 19085-19091.

24 Y. Tang, Q. Liu, L. Dong, H. Wu and X. Yu, Appl. Catal., B, 2020, 266, 118627.

25 Y. Zhao, Y. Gao, Z. Chen, Z. Li, T. Ma, Z. Wu and L. Wang, Appl. Catal., B, 2021, 297, 120395.

26 L. Zhuang, Y. Jia, H. Liu, X. Wang, R. Hocking, H. Liu, J. Chen, L. Ge, L. Zhang, M. Li, C. Dong, Y. Huang, S. Shen, D. Yang, Z. Zhu and X. Yao, Adv. Mater., 2019, 31, 1805581.

27 L. Wen, X. Zhang, J. Liu, X. Li, C. Xing, X. Lyu, W. Cai, W. Wang and Y. Li, Small, 2019, 15, 1902373.

28 Z. Wang, W. Liu, Y. Hu, M. Guan, L. Xu, H. Li, J. Bao and H. Li, Appl. Catal., B, 2020, 272, 118959.

29 G. Tomboc, J. Kim, Y. Wang, Y. Son, J. Li, J. Y. Kim and K. Lee, J. Mater. Chem. A, 2021, 9, 4528.

30 S. Liu, J. Zhu, M. Sun, Z. Ma, K. Hu, T. Nakajima, X. Liu, P. Schmuki and L. Wang, J. Mater. Chem. A, 2020, 8, 2490-2497.

31 J. Chang, G. Wang and Y. Yang, Small Sci., DOI: 10.1002/ smsc.202100044.

32 Q. Zhang, Y. Kuang, Y. Li, M. Jiang, Z. Cai, Y. Pang, Z. Chang and X. Sun, J. Mater. Chem. A, 2019, 7, 9517-9522.

33 P. Wu, Y. Wu, L. Chen, J. He, M. Hua, F. Zhu, X. Chu, J. Xiong, M. He, W. Zhu and H. Li, Chem. Eng. J., 2020, 380, 122526.

34 Z. Chen, M. Chen, X. Yan, H. Jia and R. Wu, ACS Nano, 2020, 14, 6968-6979.

35 X. Zhou, X. Li, D. Chen, D. Zhao and X. Huang, J. Mater. Chem. A, 2018, 6, 24603-24613.

36 K. Zhang, Y. Zhang, Q. Zhang, Z. Liang, L. Gu, W. Guo, B. Zhu, S. Guo and R. Zou, Carbon Energy, 2020, 2, 283-293.

37 X. Mao, A. Foucher, T. Montini, E. Stach, P. Fornasiero and R. Gorte, J. Am. Chem. Soc., 2020, 142, 10373-10382.

38 Y. Zhou, D. Yan, Q. Gu, S. Zhu, L. Wang, H. Peng and Y. Zhao, Appl. Catal., B, 2021, 285, 119792.

39 H. Sun, L. Chen, Y. Lian, W. Yang, L. Lin, Y. Chen, J. Xu, D. Wang, X. Yang, M. Rümmerli, J. Guo, J. Zhong, Z. Deng, Y. Jiao, Y. Peng and S. Qiao, Adv. Mater., 2020, 32, 2006784.

40 S. Anantharaj, S. Noda, V. R. Jothi, S. Yi, M. Driess and P. W. Menezes, Angew. Chem., Int. Ed., 2021, 60, 18981-19006.

41 Z. Wu, Y. Zhao, W. Jin, B. Jia, J. Wang and T. Ma, Adv. Funct. Mater., 2020, 31, 2009070.

42 X. Xie, L. Shang, R. Shi, G. I. N. Waterhouse, J. Zhao and T. Zhang, Nanoscale, 2020, 12, 13129-13136.

43 C. Lv, Y. Zhu, W. Zhang, W. Xu, J. Ren, H. Liu, X. Yang, R. Cai, S. Jin, D. Li and D. Yang, Mater. Today Energy, 2021, 21, 100834. 